\title{
Recommendations for the management of severe malaria and severe dengue in resource-limited settings
}

\author{
Arjen M. Dondorp ${ }^{1,2,3^{*}}$, Mai Nguyen Thi Hoang ${ }^{4}$ and Mervyn Mer ${ }^{5}$, for the Sepsis in Resource-Limited Settings- \\ Expert Consensus Recommendations Group of the European Society of Intensive Care Medicine (ESICM) and \\ the Mahidol-Oxford Research Unit (MORU) in Bangkok, Thailand
}

(c) 2016 The Author(s). This article is published with open access at Springerlink.com

\section{Introduction}

Sepsis in resource-limited settings will often have different aetiologies to those in western settings, including severe malaria, severe dengue, viral haemorrhagic fevers, mellioidosis, typhus, and leptospirosis. The Surviving Sepsis Campaign (SSC) guidelines [1] are mainly based on evidence from studies on bacterial sepsis. These guidelines are widely applicable, but there are also exceptions. We focus here on disease-specific recommendations for the management of severe falciparum malaria and severe dengue. An international team with extensive practical experience in resource-limited intensive care units (ICUs) identified key questions concerning the SSC's management recommendations on these diseases. Pertinent evidence from resource-limited settings was evaluated using the grading of recommendations assessment, development and evaluation (GRADE) tools.

\section{Recommendations for the management of severe malaria and severe dengue in resource-limited settings Severe falciparum malaria}

Severe falciparum malaria is a multi-organ disease caused by Plasmodium falciparum transmitted by Anopheles mosquitoes. The highest transmission and disease burden is in sub-Saharan Africa, where severe malaria is largely a paediatric disease, as older children and adults become partly immune. In Asia and South

\footnotetext{
*Correspondence: Arjen@tropmedres.ac

${ }^{1}$ Mahidol-Oxford Research Unit (MORU), Faculty of Tropical Medicine,

Mahidol University, Bangkok 10400, Thailand

Full author information is available at the end of the article
}

America, all age groups may be affected. Independent of age, the presenting symptoms with the strongest prognostic significance are coma (cerebral malaria), metabolic (lactic) acidosis and renal dysfunction. Hypotension occurs infrequently ( $12 \%$ of cases). One of the main pathophysiologic differences of severe falciparum malaria compared to bacterial sepsis is microcirculatory impairment caused by sequestration of parasite-infected erythrocytes, red cell rigidity and red cell clumping. Management requires rapid parasitological diagnosis by microscopy or rapid diagnostic testing (RDT) and prompt initiation of parenteral artesunate [2]. The SSC recommends that, in patients with sepsis-induced tissue hypoperfusion and suspicion of hypovolemia, with either hypotension or hyperlactatemia, an initial fluid challenge of at least $30 \mathrm{ml} / \mathrm{kg}$ of crystalloids be administered, of which a portion may be albumin equivalent [1]. Both paediatric and adult patients with severe malaria and tissue hypoperfusion are volume depleted intravascularly. A large trial on fluid bolus therapy in 3138 African children with severe infections and compensated shock, $57 \%$ of whom had falciparum malaria, showed an overall $40 \%$ increase in mortality with fluid bolus therapy ( 20 or $40 \mathrm{ml} / \mathrm{kg}$ with either saline or $5 \%$ albumin). In the 1793 children with severe $P$. falciparum malaria, mortality in the bolus groups was 51\% higher [RR 1.51 (1.17-1.95)] [3]. In Asian studies of adult severe malaria, rapid fluid resuscitation did not improve metabolic acidosis $[4,5]$ and transpulmonary thermodilution-guided rapid fluid resuscitation resulted in pulmonary oedema in $8 / 28$ (29\%) patients [5]. One observational study from Myanmar showed no deterioration in renal function or plasma 
lactate with maintenance fluid therapy between 1.3 and $2.2 \mathrm{ml} / \mathrm{kg} / \mathrm{h} \mathrm{[6]}$. We recommend against the use of fluid bolus therapy in normotensive patients with severe falciparum malaria (1A). In normotensive patients, we suggest initial ( $24 \mathrm{~h}$ ) crystalloid fluid therapy of $2-4 \mathrm{ml} /$ $\mathrm{kg} / \mathrm{h}$, which may subsequently be reduced to $1 \mathrm{ml} / \mathrm{kg} / \mathrm{h}$ in patients receiving additional fluids, e.g. through enteral tube feeding (2D). We suggest fluid bolus therapy $(30 \mathrm{ml} /$ $\mathrm{kg}$ ) with an isotonic crystalloid in patients with hypotensive shock and, if available, early initiation of vasopressor support (ungraded) (Table 1).

The SSC suggests administering enteral feeding within the first $48 \mathrm{~h}$ after diagnosing severe sepsis. In resourcelimited settings, endotracheal intubation of comatosed patients is often not practised. In a randomised trial in non-intubated predominantly adult Bangladeshi patients with cerebral malaria, early enteral feeding $(<36 \mathrm{~h})$, was associated with aspiration pneumonia in $9 / 27$ (33\%) as compared to $0 / 29$ when feeding was commenced after 60 h [7]. No difference in hypoglycaemia incidence was observed. We suggest initiating enteral feeding in nonintubated adult patients with cerebral malaria after $60 \mathrm{~h}$ (2B). There are insufficient data on paediatric patients with cerebral malaria from African settings. For patients with sepsis-induced respiratory failure, low tidal volume $(6 \mathrm{~mL} / \mathrm{kg})$ mechanical ventilation is recommended conform the SSC. In patients with cerebral malaria, we suggest against the use of permissive hypercapnia to achieve this goal, since this may exacerbate brain swelling (ungraded).

\section{Severe dengue}

Severe dengue is caused by dengue virus transmitted by Aedes mosquitoes. Approximately $1-5 \%$ of patients will develop severe manifestations. The defining feature is a vasculopathy with increased capillary permeability, causing plasma leakage, reduced intravascular volume and, if severe, life-threatening hypovolemic shock [8]. This 'critical phase' typically starts during the period of defervescense, and lasts for approximately $48 \mathrm{~h}$. Bleeding complications and organ involvement of the brain, liver, kidney and heart may be additional features, and occur more frequently in adult cases [9]. Diagnosis is commonly with combined dengue antigen (NS1) and antibody RDT [8]. No antiviral treatment is currently available (Table 1).

Unlike in bacterial sepsis, capillary leak in patients with severe dengue results in haemoconcentration. Haemorrhage, in particular from the gut, can contribute to hypovolemic shock [9]. Myocarditis is rare, but some depression of myocardial contractility is common. The World Health Organisation (WHO) guidelines on fluid resuscitation recommend restoration of the circulation guided by pulse pressure, capillary refill time, haematocrit and urine output [8]. Cautious but prompt fluid administration is essential and should be restricted

Table 1 Recommendations and suggestions for the management of patients with severe malaria and severe dengue in resource-limited settings (with grading)

We recommend not to use fluid bolus therapy in normotensive patients with severe falciparum malaria (1A). We suggest that patients receive maintenance isotonic crystalloid fluid therapy (2-4 ml/kg/h), which may subsequently be reduced to $1 \mathrm{ml} / \mathrm{kg} / \mathrm{h}$ in patients receiving additional fluids, e.g. through enteral tube feeding (2D). We suggest that, in patients with hypotensive shock, fluid bolus therapy $(30 \mathrm{ml} / \mathrm{kg})$ with isotonic crystalloids be commenced (ungraded) and, if available, early initiation of vasopressor medication (ungraded)

\begin{tabular}{|c|c|}
\hline Timing of enteral feeding in cerebral malaria & $\begin{array}{l}\text { We suggest initiating enteral feeing in non-intubated adult patients with cerebral malaria } \\
\text { after } 60 \mathrm{~h} \text {, in order to limit the possibility of aspiration pneumonia (2B). There are insuf- } \\
\text { ficient data to make this recommendation for children with cerebral malaria }\end{array}$ \\
\hline Permissive hypercapnia in ventilated cerebral malaria & $\begin{array}{l}\text { We suggest not to use a strategy of permissive hypercapnia to achieve ventilation with low } \\
\text { tidal volumes in patients with cerebral malaria, because of the high incidence of brain } \\
\text { swelling in these patients (ungraded) }\end{array}$ \\
\hline Fluid management in severe dengue & $\begin{array}{l}\text { We recommend that fluid resuscitation in severe dengue is executed promptly and guided } \\
\text { by pulse pressure, capillary refill time, haematocrit and urine output according to WHO } \\
\text { guidelines, and that fluid therapy should be restricted as soon as the critical phase of the } \\
\text { disease is over to avoid pulmonary oedema (1C). We recommend that rapid administra- } \\
\text { tion of large fluid boluses should be avoided, unless the patient is hypotensive (1D). We } \\
\text { recommend that, in dengue patients with compensated shock, colloid fluids are not used } \\
\text { (1A) }\end{array}$ \\
\hline Use of corticosteroids in severe dengue & We recommend not to use corticosteroids in the treatment of severe dengue (1B) \\
\hline Use of prophylactic platelet transfusion in severe dengue & $\begin{array}{l}\text { We recommend not to use prophylactic platelet transfusion for thrombocytopenia in the } \\
\text { absence of active bleeding complications, or other risk factors (uncontrolled arterial } \\
\text { hypertension, recent stroke, head trauma or surgery, continuation of an anticoagulant } \\
\text { treatment, or existing haemorrhagic diathesis) (1B) }\end{array}$ \\
\hline
\end{tabular}


as soon as the critical phase is over to avoid pulmonary oedema [10]. We recommend fluid administration according to the WHO guidelines (1C). We recommend that rapid ( $<30 \mathrm{~min})$ administration of large $(>15 \mathrm{ml} / \mathrm{kg})$ fluid boluses are avoided, unless the patient is hypotensive (1D). In patients with compensated shock, colloids are not superior to normal saline or Ringer's lactate for shock reversal, or for the prevention of recurrent shock, and we recommend that colloids are not used (1A) [1113]. There is insufficient evidence to recommend fluid choice in dengue hypotensive shock. The use of corticosteroids is not recommended (1B) [14]. Although thrombocytopenia is an inherent feature of severe dengue, the cause of bleeding is multifactorial, including a prominent vasculopathy. Bleeding is not prevented by platelet transfusion [15]; we do not recommend platelet transfusion for thrombocytopenia in the absence of active bleeding complications or other risk factors (1C). In cases of bleeding complications, we suggest transfusion of freshfrozen plasma (or cryoprecipitate) and platelet concentrate (ungraded).

\section{Conclusions}

The management of severe malaria and severe dengue differs in some important aspects from the treatment of bacterial sepsis, in particular, regarding fluid management.

\section{Electronic supplementary material}

The online version of this article (doi:10.1007/s00134-016-4602-2) contains supplementary material, which is available to authorized users.

\section{Author details \\ 1 Mahidol-Oxford Research Unit (MORU), Faculty of Tropical Medicine, Mahidol University, Bangkok 10400, Thailand. ${ }^{2}$ Oxford Centre for Tropical Medicine and Global Health, Nuffield Department of Clinical Medicine, University of Oxford, Oxford, UK. ${ }^{3}$ Department of Intensive Care, Academic Medical Center, University of Amsterdam, Amsterdam, The Netherlands. ${ }^{4}$ Oxford Uni- versity Clinical Research Unit, Hospital for Tropical Diseases, Ho Chi Minh City, Vietnam. ${ }^{5}$ Department of Critical Care, Johannesburg Hospital and University of the Witwatersrand, Johannesburg, South Africa.}

\section{Acknowledgements}

Dengue and malaria subgroup members: Sanjib Mohanty (Ispat General Hospital, Rourkela, Sundargarh, Odisha, India), Marcus Schultz (Academic Medical Center, University of Amsterdam, Amsterdam, The Netherlands and Faculty of Tropical Medicine, Mahidol University, Bangkok, Thailand), Louise Thwaites (Centre for Tropical Medicine and Global Health, Nuffield Department of Medicine, University of Oxford, Oxford, UK), Martin Dünser (Department of Critical Care, University College of London Hospital, London, UK), Jane Nakibuuka (Mulago National Referral and University Teaching Hospital, Kampala, Uganda). We thank Prof. Bridget Wills for her input on the recommendations for severe dengue management.

Open Access This article is distributed under the terms of the Creative Commons Attribution 4.0 International License (http://creativecommons.org/ licenses/by/4.0/), which permits use, duplication, adaptation, distribution and reproduction in any medium or format, as long as appropriate credit is given to the original author(s) and the source, a link is provided to the Creative Commons license and any changes made are indicated.
Received: 5 September 2016 Accepted: 19 October 2016

Published online: 5 November 2016

\section{References}

1. Dellinger RP, Levy MM, Rhodes A, Annane D, Gerlach H, Opal SM, Sevransky JE, Sprung CL, Douglas IS, Jaeschke R, Osborn TM, Nunnally ME, Townsend SR, Reinhart K, Kleinpell RM, Angus DC, Deutschman CS, Machado FR, Rubenfeld GD, Webb S, Beale RJ, Vincent JL, Moreno R (2013) Surviving Sepsis Campaign: international guidelines for management of severe sepsis and septic shock, 2012. Intensive Care Med 39:165-228

2. WHO (2014) Severe malaria. Trop Med Int Health 19:7-131

3. Maitland K, Kiguli S, Opoka RO, Engoru C, Olupot-Olupot P, Akech SO, Nyeko R, Mtove G, Reyburn H, Lang T, Brent B, Evans JA, Tibenderana JK, Crawley J, Russell EC, Levin M, Babiker AG, Gibb DM (2011) Mortality after fluid bolus in African children with severe infection. N Engl J Med 364:2483-2495

4. Nguyen HP, Hanson J, Bethell D, Nguyen TH, Tran TH, Ly VC, Pham PL, Dinh XS, Dondorp A, White N, Day N (2011) A retrospective analysis of the haemodynamic and metabolic effects of fluid resuscitation in Vietnamese adults with severe falciparum malaria. PLoS ONE 6:e25523

5. Hanson JP, Lam SW, Mohanty S, Alam S, Pattnaik R, Mahanta KC, Hasan MU, Charunwatthana P, Mishra SK, Day NP, White NJ, Dondorp AM (2013) Fluid resuscitation of adults with severe falciparum malaria: effects on acid-base status, renal function, and extravascular lung water. Crit Care Med 41:972-981

6. Aung NM, Kaung M, Kyi TT, Kyaw MP, Min M, Htet ZW, Anstey NM, Kyi MM, Hanson J (2015) The safety of a conservative fluid replacement strategy in adults hospitalised with malaria. PLoS ONE 10:e0143062

7. Maude RJ, Hoque G, Hasan MU, Sayeed A, Akter S, Samad R, Alam B, Yunus EB, Rahman R, Rahman W, Chowdhury R, Seal T, Charunwatthana P, Chang CC, White NJ, Faiz MA, Day NP, Dondorp AM, Hossain A (2011) Timing of enteral feeding in cerebral malaria in resource-poor settings: a randomized trial. PLOS ONE 6:e27273

8. WHO (2009) Dengue: guidelines for treatment, prevention and control. Dengue. World Health Organization, Geneva. http://apps.who.int/iris/ bitstream/10665/44188/1/9789241547871_eng.pdf

9. Simmons CP, Farrar JJ, van Nguyen V, Wills B (2012) Dengue. N Engl J Med 366:1423-1432

10. Lam PK, Tam DT, Diet TV, Tam CT, Tien NT, Kieu NT, Simmons C, Farrar J, Nga NT, Qui PT, Dung NM, Wolbers M, Wills B (2013) Clinical characteristics of dengue shock syndrome in Vietnamese children: a 10-year prospective study in a single hospital. Clin Infect Dis 57:1577-1586

11. Wills BA, Nguyen MD, Ha TL, Dong TH, Tran TN, Le TT, Tran VD, Nguyen TH, Nguyen VC, Stepniewska K, White NJ, Farrar JJ (2005) Comparison of three fluid solutions for resuscitation in dengue shock syndrome. N Engl J Med 353:877-889

12. Dung NM, Day NP, Tam DT, Loan HT, Chau HT, Minh LN, Diet TV, Bethell DB, Kneen R, Hien TT, White NJ, Farrar JJ (1999) Fluid replacement in dengue shock syndrome: a randomized, double-blind comparison of four intravenous-fluid regimens. Clin Infect Dis 29:787-794

13. Ngo NT, Cao XT, Kneen R, Wills B, Nguyen VM, Nguyen TQ, Chu VT, Nguyen TT, Simpson JA, Solomon T, White NJ, Farrar J (2001) Acute management of dengue shock syndrome: a randomized double-blind comparison of four intravenous fluid regimens in the first hour. Clin Infect Dis 32:204-213

14. Panpanich R, Sornchai P, Kanjanaratanakorn K (2006) Corticosteroids for treating dengue shock syndrome. Cochrane Database Syst Rev CD003488

15. Lye DC, Lee VJ, Sun Y, Leo YS (2009) Lack of efficacy of prophylactic platelet transfusion for severe thrombocytopenia in adults with acute uncomplicated dengue infection. Clin Infect Dis 48:1262-1265 